\title{
Article \\ Anti-Biofilm Coatings Based on Chitosan and Lysozyme Functionalized Magnetite Nanoparticles
}

\author{
Vera Alexandra Spirescu ${ }^{1}$, Adelina-Gabriela Niculescu ${ }^{1}$, S Ștefan Slave ${ }^{1}$, Alexandra Cătalina Bîrcă ${ }^{1}$, \\ Gabriela Dorcioman ${ }^{2}$, Valentina Grumezescu ${ }^{2}$, Alina Maria Holban ${ }^{3}$, Ovidiu-Cristian Oprea ${ }^{4}(\mathbb{B}$, \\ Bogdan Ștefan Vasile ${ }^{1} \mathbb{D}^{\infty}$, Alexandru Mihai Grumezescu ${ }^{1,5,6, *}{ }^{\mathbb{D}}$, Ionela Cristina Nica ${ }^{6,7}$, \\ Miruna Silvia Stan ${ }^{6,7}(\mathbb{D}$ and Ecaterina Andronescu $1,6[$
}

Citation: Spirescu, V.A.; Niculescu,

A.-G.; Slave, S.; Bîrcă, A.C.;

Dorcioman, G.; Grumezescu, V.;

Holban, A.M.; Oprea, O.-C.; Vasile,

B.Ș.; Grumezescu, A.M.; et al.

Anti-Biofilm Coatings Based on

Chitosan and Lysozyme

Functionalized Magnetite

Nanoparticles. Antibiotics 2021, 10,

1269. https://doi.org/10.3390/

antibiotics10101269

Academic Editor: Hao Song

Received: 15 September 2021

Accepted: 15 October 2021

Published: 19 October 2021

Publisher's Note: MDPI stays neutral with regard to jurisdictional claims in published maps and institutional affiliations.

Copyright: (c) 2021 by the authors. Licensee MDPI, Basel, Switzerland. This article is an open access article distributed under the terms and conditions of the Creative Commons Attribution (CC BY) license (https:/ / creativecommons.org/licenses/by/ $4.0 /)$.
1 Department of Science and Engineering of Oxide Materials and Nanomaterials, University Politehnica of Bucharest, 011061 Bucharest, Romania; veraspirescu@stud.fim.upb.ro (V.A.S.); adelina.niculescu@stud.fils.upb.ro (A.-G.N.); stefan.slave@gmail.com (S.S.); alexandra.birca@upb.ro (A.C.B.); bogdan.vasile@upb.ro (B.S..V.); ecaterina.andronescu@upb.ro (E.A.)

2 Lasers Department, National Institute for Lasers, Plasma and Radiation Physics, 077125 Magurele, Romania; gabriela.dorcioman@inflpr.ro (G.D.); valentina.grumezescu@inflpr.ro (V.G.)

3 Department of Microbiology and Immunology, Faculty of Biology, University of Bucharest, 077206 Bucharest, Romania; alina.m.holban@bio.unibuc.ro

4 Department of Inorganic Chemistry, Physical Chemistry and Electrochemistry, Faculty of Applied Chemistry and Materials Science, Politehnica University of Bucharest, 011061 Bucharest, Romania; ovidiu.oprea@upb.ro

5 Research Institute of the University of Bucharest-ICUB, University of Bucharest, 050657 Bucharest, Romania

6 Academy of Romanian Scientists, Ilfov No. 3, 50044 Bucharest, Romania; cristina.nica@drd.unibuc.ro (I.C.N.); miruna.stan@bio.unibuc.ro (M.S.S.)

7 Department of Biochemistry and Molecular Biology, Faculty of Biology, University of Bucharest, 050095 Bucharest, Romania

* Correspondence: agrumezescu@upb.ro

\begin{abstract}
Biofilms represent a common and increasingly challenging problem in healthcare practices worldwide, producing persistent and difficult to manage infections. Researchers have started developing antibiotic-free treatment alternatives in order to decrease the risk of resistant microbial strain selection and for the efficient management of antibiotic tolerant biofilm infections. The present study reports the fabrication and characterization of magnetite-based nanostructured coatings for producing biofilm-resistant surfaces. Specifically, magnetite nanoparticles $\left(\mathrm{Fe}_{3} \mathrm{O}_{4}\right)$ were functionalized with chitosan (CS) and were blended with lysozyme (LyZ) and were deposited using the matrixassisted pulsed laser evaporation (MAPLE) technique. A variety of characterization techniques were employed to investigate the physicochemical properties of both nanoparticles and nanocoatings. The biological characterization of the coatings assessed through cell viability and antimicrobial tests showed biocompatibility on osteoblasts as well as antiadhesive and antibiofilm activity against both Gram-negative and Gram-positive bacterial strains and no cytotoxic effect against human-cultured diploid cells.
\end{abstract}

Keywords: laser processing; lysozyme; magnetite-based coatings; nanostructured bioactive coatings; antimicrobial properties; antibiofilm activity

\section{Introduction}

As revealed by the National Institutes of Health (NIH), 65\% of all microbial infections and $80 \%$ of all chronic infections are associated with biofilm formation [1]. Thus, biofilms retain a relevant impact on public health, increasing hospital costs and resulting in significant morbidity and mortality [2-4].

Specifically, biofilms represent multicellular, surface-associated communities of microorganisms that self-produce extracellular polymeric substances (EPS) that mainly consist of polysaccharides, extracellular DNA, and proteins $[3,5,6]$. The polymeric matrix offers 
protection and enhanced survival abilities, shielding them from the host's immune system, hindering the diffusion of antimicrobial agents to the biofilm, and leading to poor treatment outcomes [7-9]. Moreover, biofilm-protected bacteria can be released, which is conducive to the appearance of new infection sites [7].

The burden of biofilm development must be especially considered for indwelling and implanted medical devices, including catheters, mechanical heart valves, pacemakers, stents, prosthetic joints and implants, voice prosthesis, and internal and external fixation devices $[1-3,8,10]$. The conventional approach for treating device-associated infections consists of the prophylactic administration of systemic antibiotics and debridement $[10,11]$. However, bacterial cells in biofilms can exhibit a 1000-fold or greater increase in antibiotic resistance compared to planktonic cells, thus limiting the efficiency of classic therapies [3,5,12]. Moreover, the inappropriate prescription and inadequate administration of antimicrobial therapeutics may lead to side effects, organ toxicity, and ever-increasing antibiotic resistance [10,13-15].

Because biofilm-related infections are very difficult to eradicate, the recent research focus was shifted towards preventing biofilm formation [16,17]. In particular, modification of the surface nanotopography of biomedical devices represents a promising strategy against microbial adhesion [18]. By incorporating antimicrobial nanocompounds within or on the surface of materials or by coating the implants with a bioactive nanostructured film, the surface can be optimized towards impeding microbial adhesion or destroying pathogens after their attachment $[7,11,14,19,20]$. Nanomaterials are currently being investigated for numerous biomedical applications, including diagnosis and therapy [21,22], and are considered to be a versatile and innovative strategy for the management of infectious diseases [23].

The high potential in many applications of iron oxide nanoparticles is the result of the combination of their magnetic properties with biocompatibility, reactive surface, stability, and so on. Based on their unique properties, iron oxide nanoparticles have attracted considerable interest in the last decade [24-26]. Among them, $\mathrm{Fe}_{3} \mathrm{O}_{4}$ is one of the most popular types of currently researched nanomaterials, especially due to its special magnetic properties, availability, versatility, eco-friendliness, and low cost. Moreover, their small size, excellent biocompatibility, biodegradability, non-toxicity to humans, and possibility for functionalization these bioactive magnetic make these nanostructures recommended for the development of unconventional antimicrobials [27-31]. Nevertheless, the properties of $\mathrm{Fe}_{3} \mathrm{O}_{4}$ nanoparticles depend on their preparation method, and many synthesis techniques have been employed to obtain optimal characteristics for different end purposes. Methods, such as co-precipitation, thermal decomposition, sol-gel, microemulsion, hydrothermal, sonochemical, electrochemical, and biological synthesis have been shown to successfully produce $\mathrm{Fe}_{3} \mathrm{O}_{4}$ nanostructures [24,28,32-34]. One of the simplest and most widely used chemical methods for obtaining nanosized $\mathrm{Fe}_{3} \mathrm{O}_{4}$ is co-precipitation [35-37], particularly due to its simplicity, high yields, and potential for reduced time-consuming, making it easily scalable in industrial applications [37]. Moreover, particle properties can be tuned by carefully adjusting the ratio of iron salts and the $\mathrm{pH}$ of the reaction medium $[23,38,39]$.

Nonetheless, $\mathrm{Fe}_{3} \mathrm{O}_{4}$ nanoparticles are not stable in air, having a tendency to oxidize to maghemite, and can easily agglomerate after production. To avoid these drawbacks, $\mathrm{Fe}_{3} \mathrm{O}_{4}$ nanoparticles for biomedical purposes are usually protected by shells of different biocompatible materials, such as natural polysaccharides, inert synthetic materials, and organic acids with different structures $[27,28,40]$. From the plethora of materials that can be used to modify the surface of $\mathrm{Fe}_{3} \mathrm{O}_{4}$ nanoparticles, chitosan is one of the most attractive options.

Chitosan is a partially deacetylated linear polysaccharide of chitin [41]. Its natural origin and convenient biochemical properties (e.g., good tolerability, non-toxicity, good biocompatibility, proper biodegradation rate, antioxidant activity, antimicrobial activity) make this cationic polymer recommended for various biomedical applications [24,42-52]. Lysozyme is an important antibacterial component, catalytically hydrolyzing $\beta(1 \rightarrow 4)$ 
glycosidic linkages at the $\mathrm{C}_{4}$ atom within the $\mathrm{N}$-acetyl-D-glucosamine units present in chitosan. This catalytic hydrolysis justifies the antibacterial nature of lysozyme, as it selectively degrades the cell walls of microorganisms without destroying other tissues $[53,54]$. More recently, several studies have investigated the effects of chitosan-lysozyme conjugates on bacterial strains $[55,56]$.

In this context, we report the fabrication of novel biocompatible coatings with inhibitory activity against microbial biofilm formation based on $\mathrm{Fe}_{3} \mathrm{O}_{4}$ nanoparticles functionalized with chitosan and lysozyme by MAPLE (matrix-assisted pulsed laser evaporation) technique. We have selected this laser processing method because of its versatility, ability to obtain thin and uniform bioactive coatings, and the fact that it allows the deposition of virtually any type of chemical target while maintaining the properties of all the involved bioactives during processing $[11,14]$. The obtained nanocomposites were investigated from the compositional, morphological, and biological points of view by employing X-ray diffraction (XRD), thermogravimetric analysis with differential scanning calorimetry (TGADSC), scanning electron microscopy (SEM), transmission electron microscopy with selected area electron diffraction (TEM-SAED), Fourier-transform infrared spectroscopy (FT-IR), infrared microscopy (IRM), cell viability, and antimicrobial tests. Results have shown that the obtained thin nanostructured coatings could be considered for the future development of antibiofilm surfaces, showing great potential in prosthetics and regenerative medicine.

\section{Results and Discussions}

\subsection{Physicochemical Investigation of $\mathrm{Fe}_{3} \mathrm{O}_{4} @ \mathrm{CS}$ Nanoparticles}

The XRD pattern of the $\mathrm{Fe}_{3} \mathrm{O}_{4} @ C S$ nanoparticles is presented in Figure 1. The strong diffraction peaks appearing at $2 \theta$ diffraction angles of $30.0^{\circ}, 35.4^{\circ}, 44.0^{\circ}, 53.4^{\circ}, 56.9^{\circ}$, and

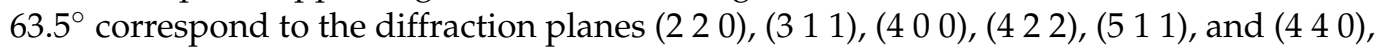
respectively, which is characteristic for crystalline magnetite with a spinel cubic structure. The strongest peak in the diffractogram is identified for a $2 \theta$ angle of $30^{\circ}$. All of the peaks are in agreement with the standard spectrum of $\mathrm{Fe}_{3} \mathrm{O}_{4}$ (DB card No. 9006242).

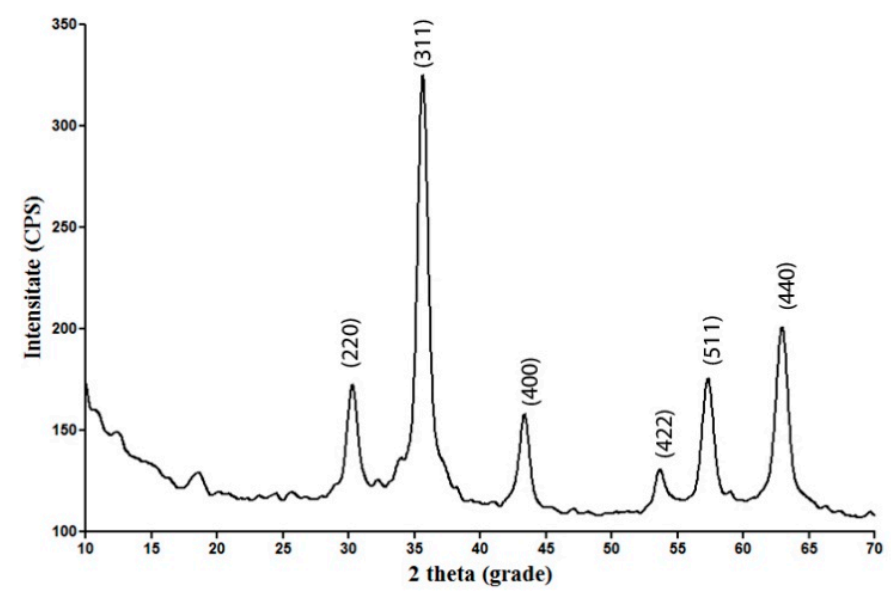

Figure 1. X-ray diffractogram of $\mathrm{Fe}_{3} \mathrm{O}_{4} @ \mathrm{CS}$ nanoparticles.

The TEM investigation gathered relevant information on the distribution and composition of the crystalline phase in the samples of the $\mathrm{Fe}_{3} \mathrm{O}_{4} @ \mathrm{CS}$ particles (Figure 2). From the micrographs recorded at $20 \mathrm{~nm}$ and $10 \mathrm{~nm}$, the homogeneous distribution of the magnetite nanoparticles embedded in the chitosan matrix can be observed. Furthermore, TEM images confirm that the dimension of the particles is at the nanoscale, showing their organization in areas where the particles are dispersed.

The SAED pattern of the concentric diffraction rings formed at 220, 311, 400, 422, 511, and 440 are in excellent agreement with the results of the XRD analysis, thus confirming the crystalline nature of the prepared magnetite (Figure 2d). 


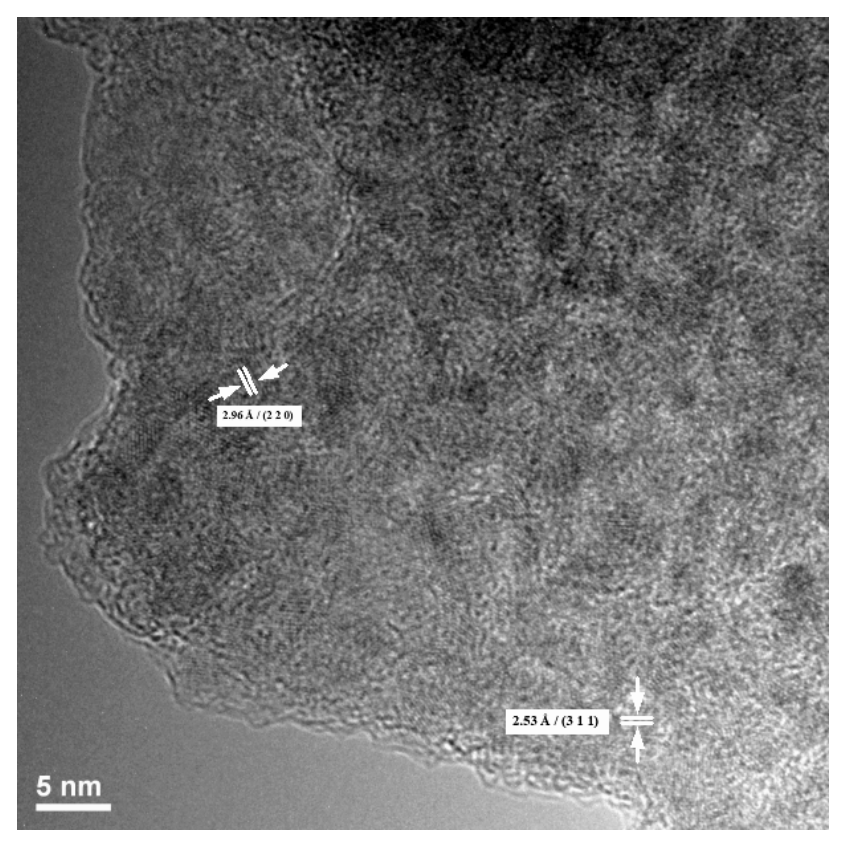

(a)

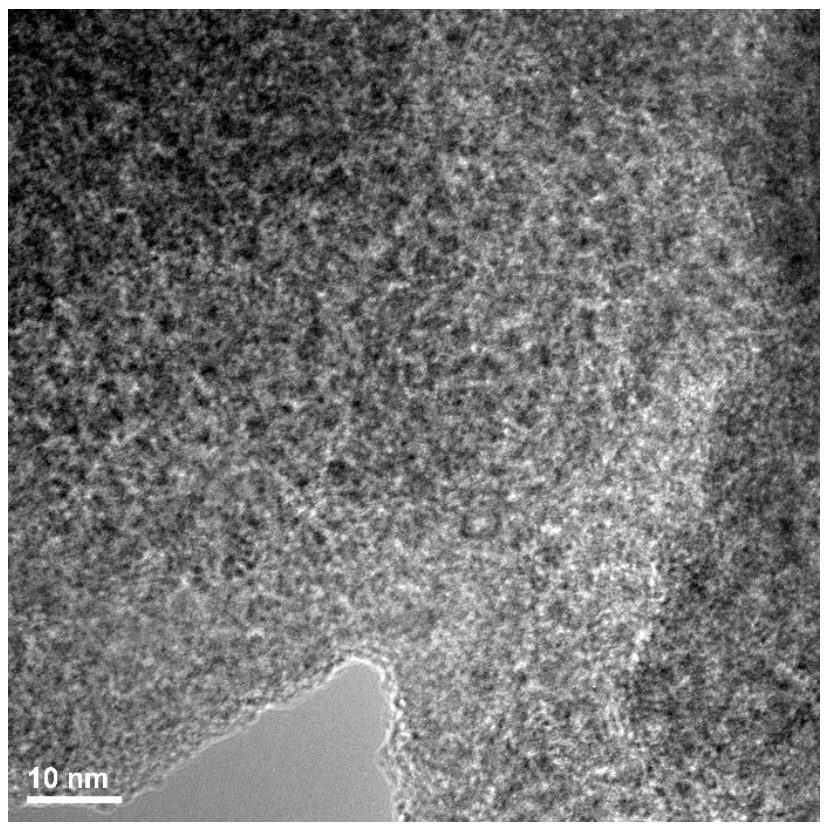

(c)

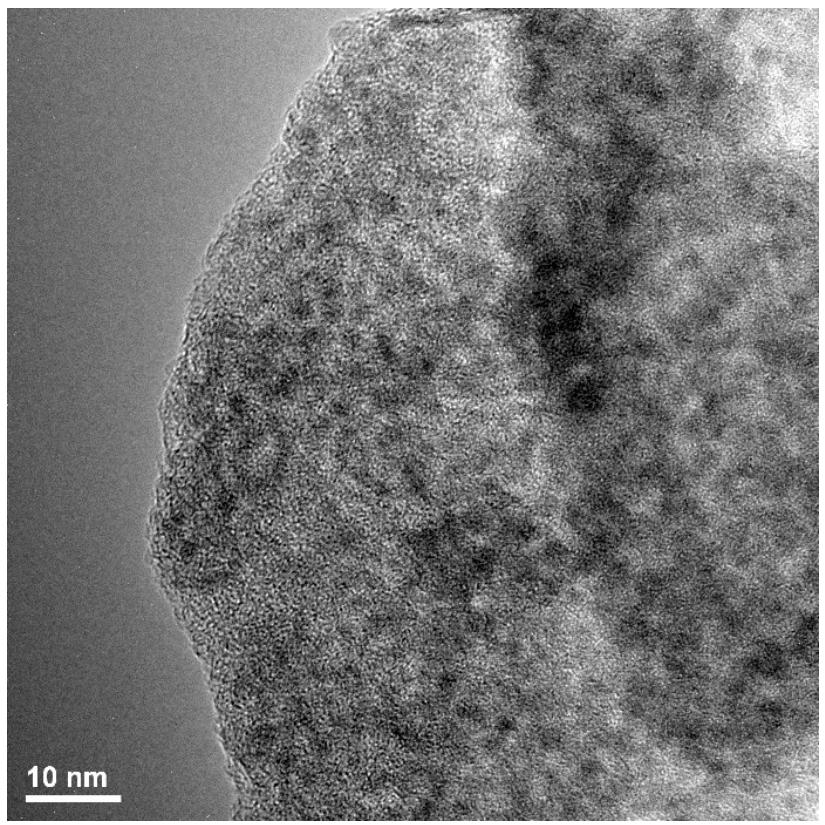

(b)

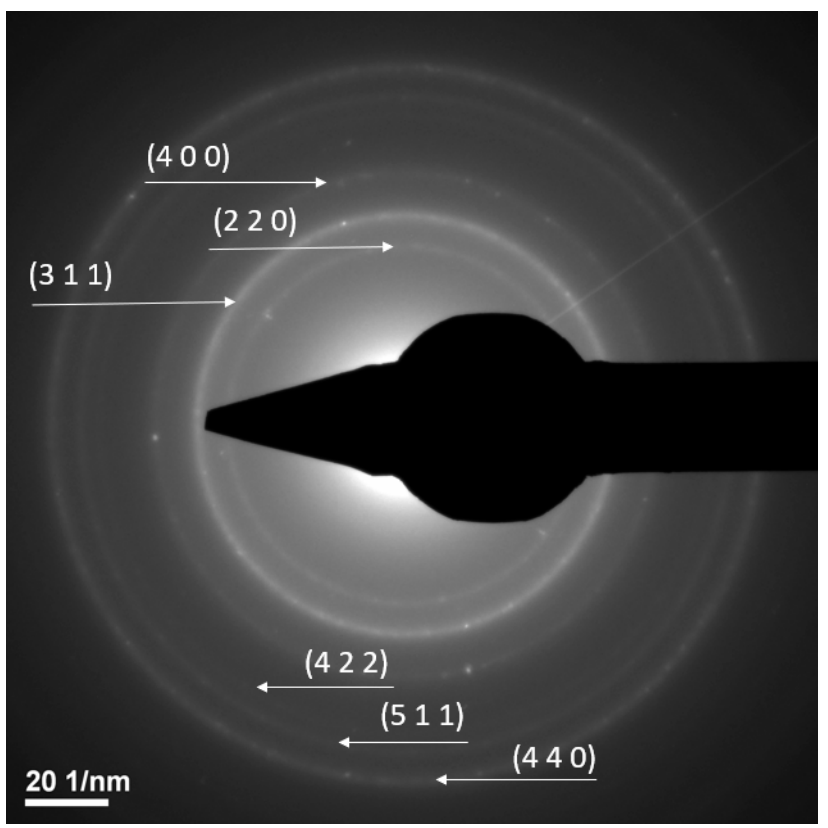

(d)

Figure 2. TEM images $(\mathbf{a}-\mathbf{c})$ and SAED pattern $(\mathbf{d})$ of $\mathrm{Fe}_{3} \mathrm{O}_{4} @ \mathrm{CS}$ nanoparticles.

The FT-IR analysis highlighted the integrity of the main functional groups of the prepared $\mathrm{Fe}_{3} \mathrm{O}_{4} @ \mathrm{CS}$ nanocomposite (Figure 3). The absorption band recorded at $541 \mathrm{~cm}^{-1}$ corresponds to the $\mathrm{Fe}-\mathrm{O}$ stretching vibrations from the structure of the magnetite; the absorption bands between 1088 and $3368 \mathrm{~cm}^{-1}$ are generated by the functional bonds from the structure of the chitosan, namely $\mathrm{C}-\mathrm{O}\left(1088 \mathrm{~cm}^{-1}\right), \mathrm{C}=\mathrm{O}\left(1637 \mathrm{~cm}^{-1}\right)$, and C-H $\left(2857 \mathrm{~cm}^{-1}\right.$ and $\left.2931 \mathrm{~cm}^{-1}\right)$. The absorption band that is characteristic to the hydroxyl and amino groups is observed at $3368 \mathrm{~cm}^{-1}$.

A thermal analysis was realized on pristine and $\mathrm{Fe}_{3} \mathrm{O}_{4} @ \mathrm{CS}$ (Figure 4). From Figure 4b, it can be seen that in the interval of RT- $150{ }^{\circ} \mathrm{C}$, the $\mathrm{Fe}_{3} \mathrm{O}_{4} @ \mathrm{CS}$ sample loses $1.89 \%$ of its initial mass. The process is accompanied by an endothermic effect on the DSC curve, 
with the minimum at $89.6^{\circ} \mathrm{C}$. This mass loss can be assigned to the elimination of water molecules from the chitosan matrix and the surface of the nanoparticles. In the $150-450{ }^{\circ} \mathrm{C}$ interval, the sample loses $2.01 \%$ of its mass, which is probably due to the elimination of the -OH moieties from the nanoparticle surface but is also probably due to the oxidative degradation of the organic parts [57]. The weak exothermic effect from $223.8^{\circ} \mathrm{C}$ can be assigned to the oxidation of $\mathrm{Fe}^{2+}$ to $\mathrm{Fe}^{3+}$ (transformation of magnetite to maghemite). The exothermic effect from $335.7^{\circ} \mathrm{C}$ can be attributed to the oxidation of the chitosan [58]. After $450{ }^{\circ} \mathrm{C}$, the sample loses $0.14 \%$ of its initial mass. The intense exothermic effect from $561.6^{\circ} \mathrm{C}$ is due to the phase transformation of maghemite to hematite [14,59]. This thermal behavior pattern is similar to the one of the bare $\mathrm{Fe}_{3} \mathrm{O}_{4}$ particles (Figure 4a).

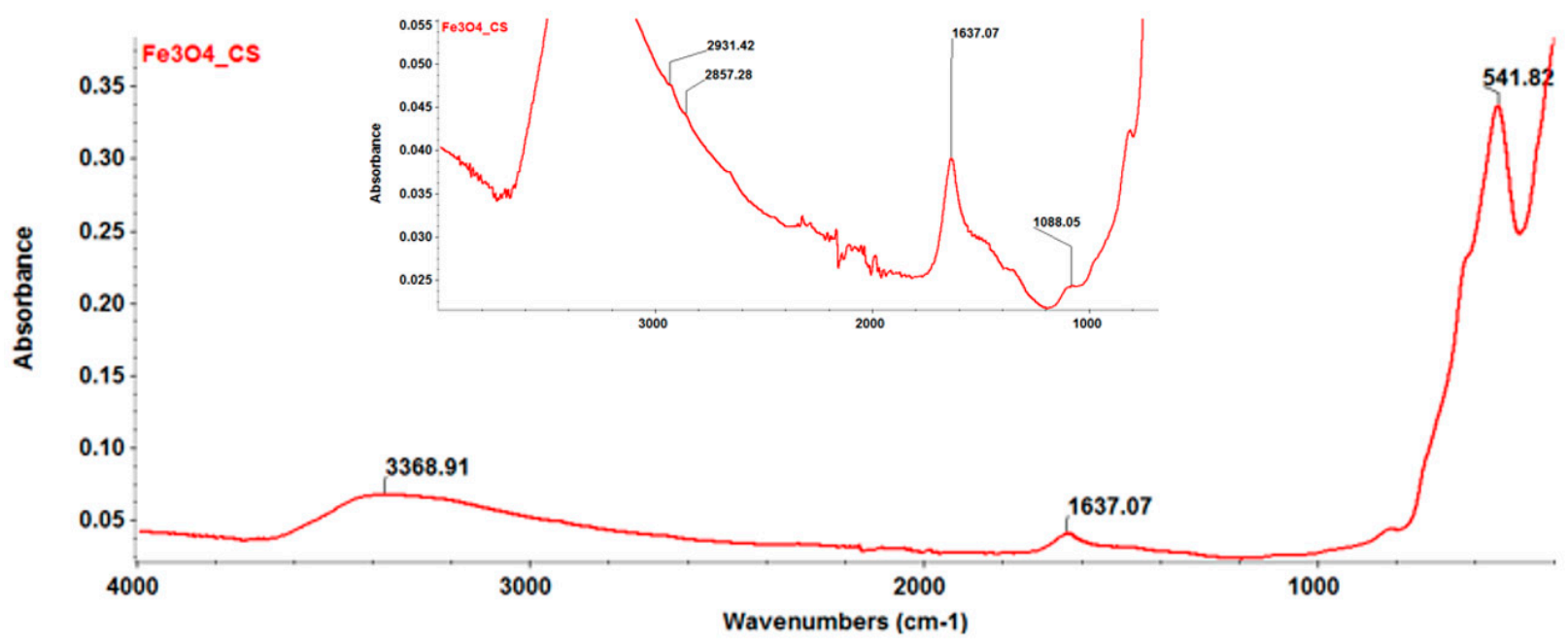

Figure 3. FT-IR spectrum of $\mathrm{Fe}_{3} \mathrm{O}_{4} @ \mathrm{CS}$ nanoparticles.

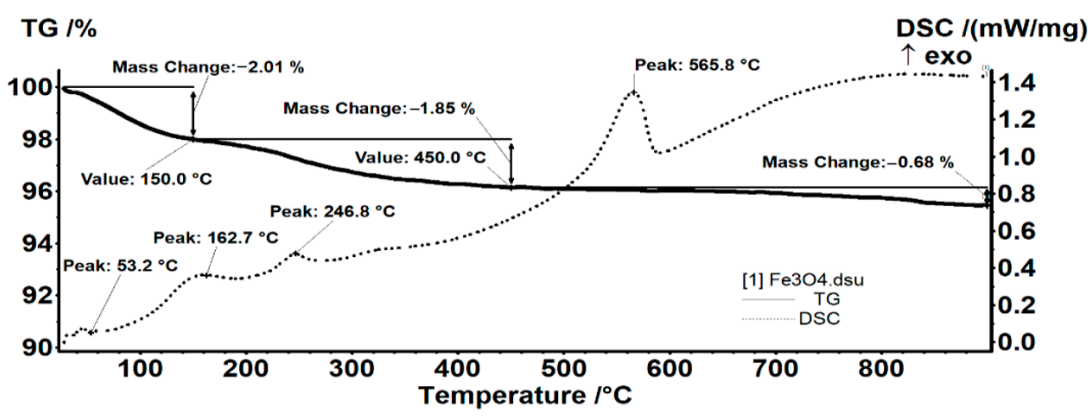

(a)

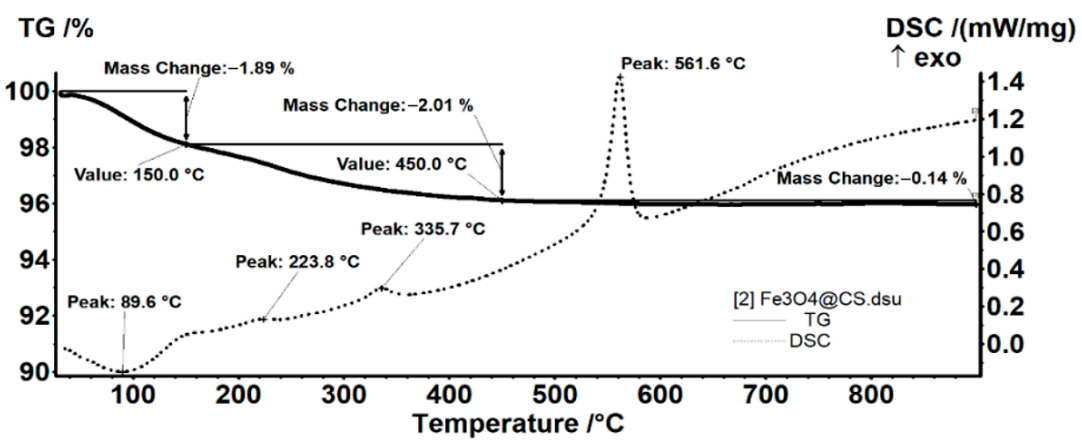

(b)

Figure 4. Thermogravimetric analysis of (a) $\mathrm{Fe}_{3} \mathrm{O}_{4}$ and (b) $\mathrm{Fe}_{3} \mathrm{O}_{4} @ \mathrm{CS}$ nanoparticles. 


\subsection{Physicochemical Investigation of the Coatings}

The thin coatings were characterized using IRM analysis. In this respect, IR maps were recorded for the $\mathrm{Fe}_{3} \mathrm{O}_{4} @ \mathrm{CS}$ drop-cast (Figure 5a), and coatings were obtained at the 300, 400 , and $500 \mathrm{~mJ} / \mathrm{cm}^{2}$ laser fluences (Figure $5 \mathrm{~b}-\mathrm{d}$ ) to allow a comparative analysis of the chemical distribution. The absorbance intensities of the IR spectra maps are proportional to color changes starting with blue (the lowest intensity) and gradually increasing through green, yellow, to finally red (the highest intensity). Thus, by comparing the IRM, it can be observed that the lowest functional group degradation was recorded at the $400 \mathrm{~mJ} / \mathrm{cm}^{2}$ laser fluence. At this fluence, the color distribution is better than that of the other two laser fluences, showing that the thin coatings were deposited in the most homogeneous and uniform layer.

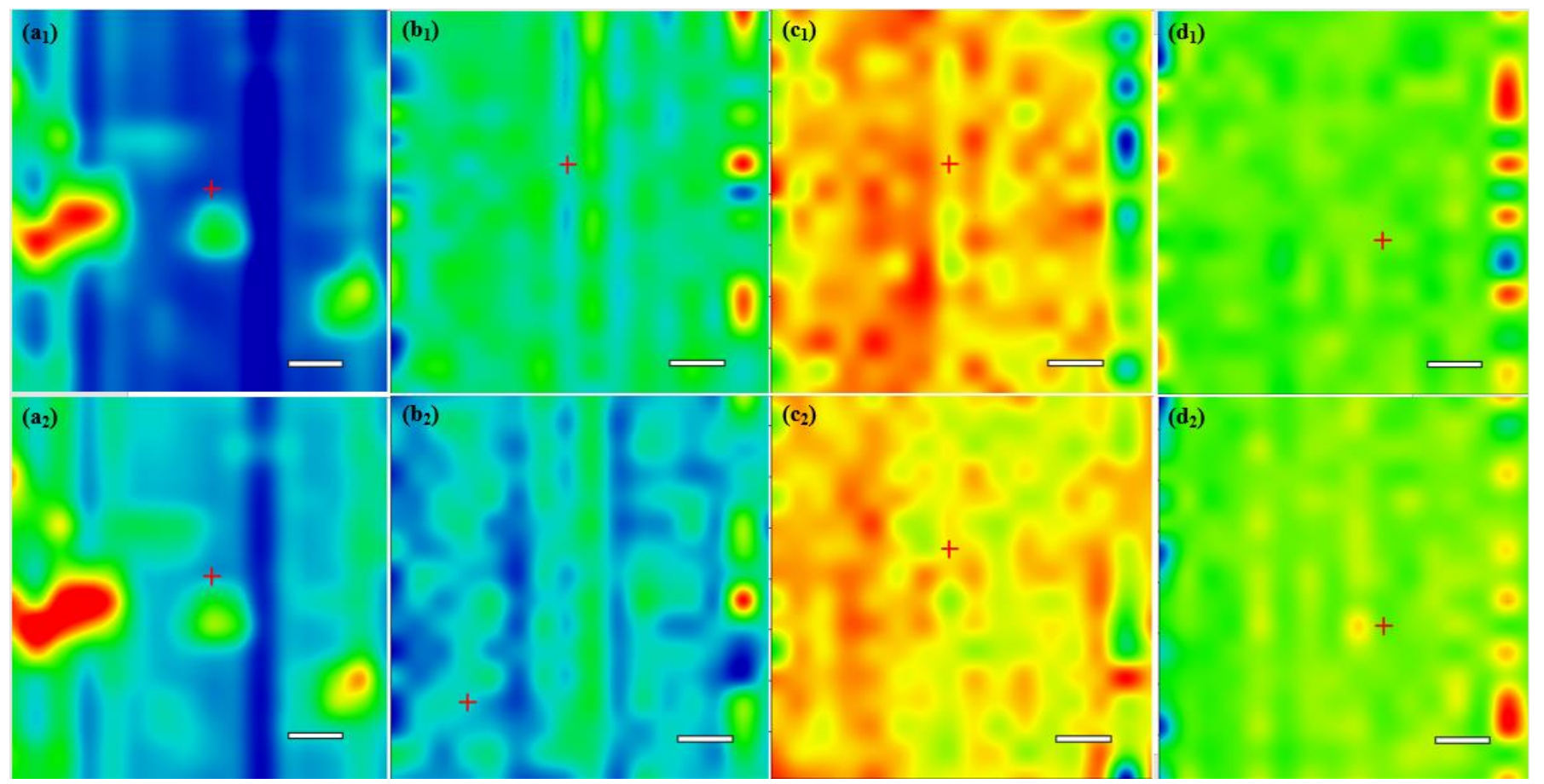

Figure 5. IRM of $\mathrm{Fe}_{3} \mathrm{O}_{4} @ \mathrm{CS}$ drop-cast (a) and $\mathrm{Fe}_{3} \mathrm{O}_{4} @ \mathrm{CS}$ thin coatings at $300 \mathrm{~mJ} / \mathrm{cm}^{2}(\mathbf{b}), 400 \mathrm{~mJ} / \mathrm{cm}^{2}(\mathbf{c})$, and $500 \mathrm{~mJ} / \mathrm{cm}^{2}$ (d) based on the distribution of C-H (1) and C-N (2) bonds from CS; scale bar $100 \mu \mathrm{m}$.

Similar observations were made by comparing the IRM of the $\mathrm{Fe}_{3} \mathrm{O}_{4} @ \mathrm{CS} /$ LyZ coatings (Figure 6).

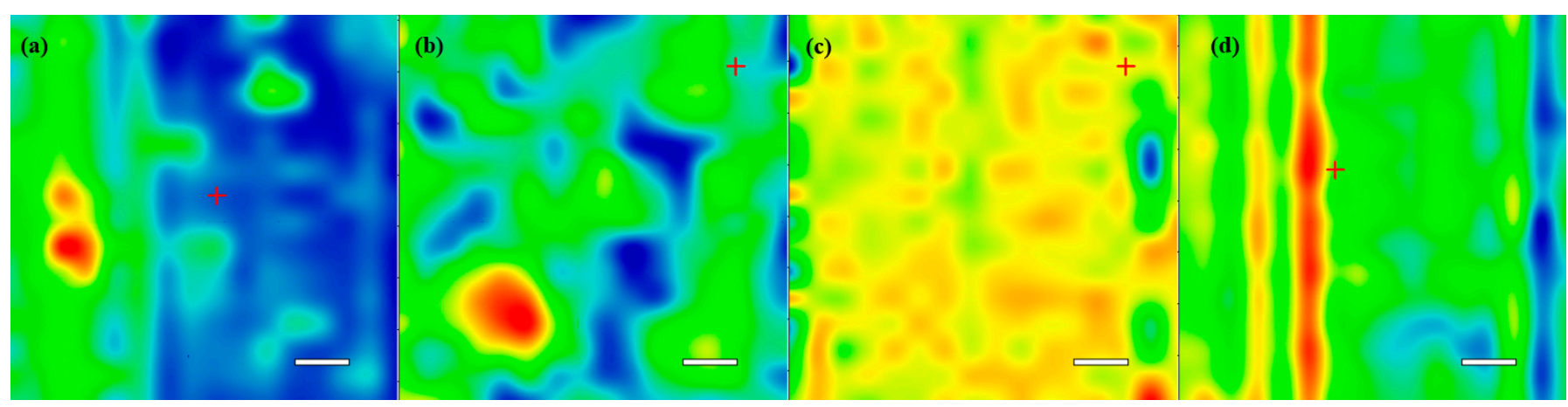

Figure 6. IRM of $\mathrm{Fe}_{3} \mathrm{O}_{4} @ \mathrm{CS} / \mathrm{LyZ}$ drop-cast (a) and $\mathrm{Fe}_{3} \mathrm{O}_{4} @ \mathrm{CS} / \mathrm{LyZ}$ thin coatings at $300 \mathrm{~mJ} / \mathrm{cm}^{2}$ (b), $400 \mathrm{~mJ} / \mathrm{cm}^{2}$ (c), and $500 \mathrm{~mJ} / \mathrm{cm}^{2}$ (d) based on the distribution of C-N bonds from CS and LyZ; scale bar $100 \mu \mathrm{m}$. 
Complementary information was provided by analyzing the IR spectra of the $\mathrm{Fe}_{3} \mathrm{O}_{4} @ \mathrm{CS}$ (data not shown) and the $\mathrm{Fe}_{3} \mathrm{O}_{4} @ \mathrm{CS} / \mathrm{LyZ}$ drop-cast and coatings obtained at 300, 400, and $500 \mathrm{~mJ} / \mathrm{cm}^{2}$. The $\mathrm{Fe}_{3} \mathrm{O}_{4} @ \mathrm{CS}$ and $\mathrm{Fe}_{3} \mathrm{O}_{4} @ \mathrm{CS} / \mathrm{LyZ}$ coatings recorded the lowest degree of functional group degradation at $400 \mathrm{~mJ} / \mathrm{cm}^{2}$ laser fluence (Figure 7). For the other two laser fluences at which the magnetite-based layers were deposited, modifications in the intensities of the absorption bands can be observed. The decreases in the absorbance maxima, compared to drop-cast spectra, can be attributed to an insufficient transfer of the composite materials. In contrast, the loss and position shifting of some infrared maxima indicates that the laser beam damaged the chemical structure of the transferred material.
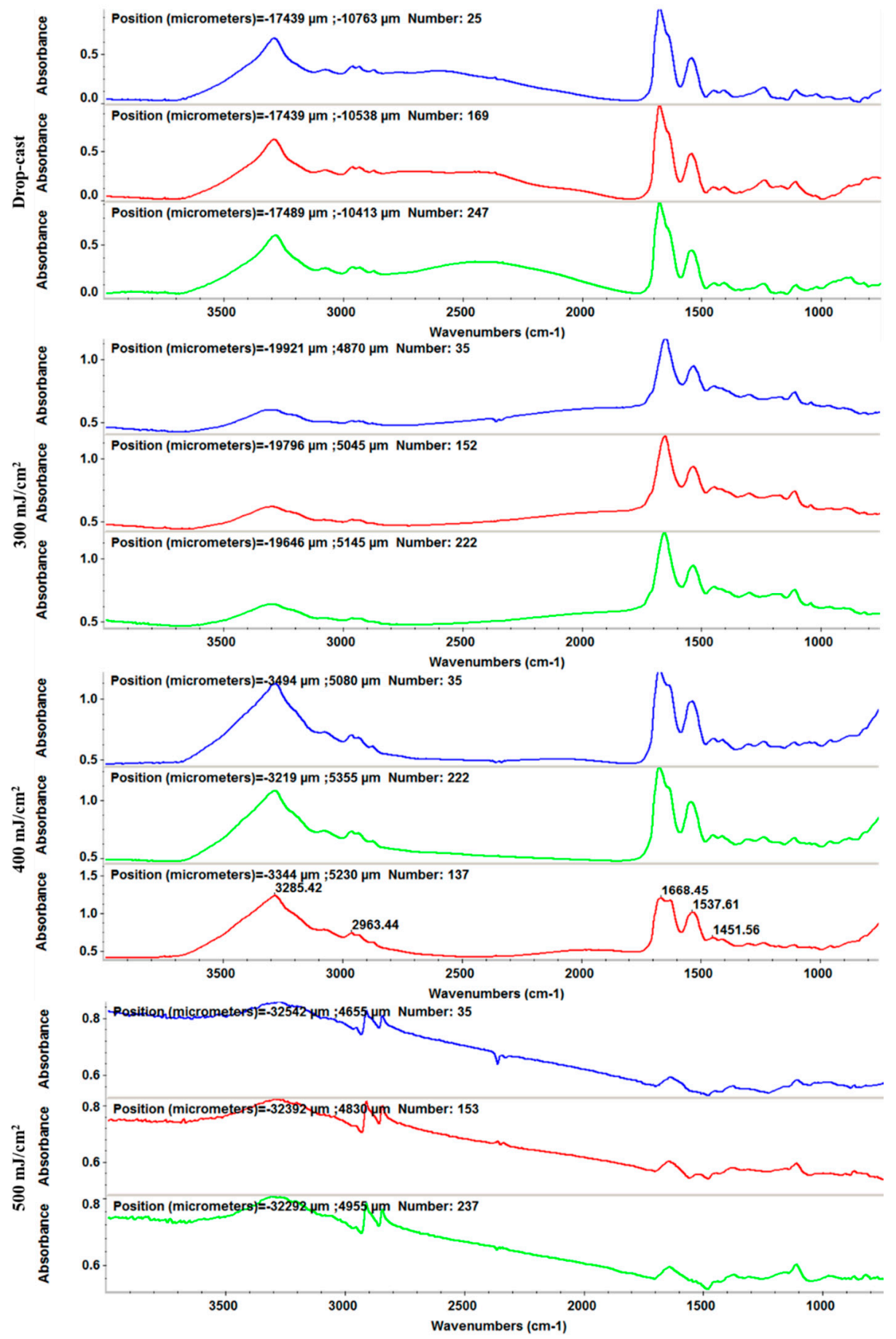

Figure 7. IR spectra of $\mathrm{Fe}_{3} \mathrm{O}_{4} @ \mathrm{CS} / \mathrm{LyZ}$ drop-cast and coatings obtained at differences laser fluence. 
Analyzing the integrity of IR spectra for each sample deposited at different laser fluences and the corresponding drop-cast coating, we selected the $400 \mathrm{~mJ} / \mathrm{cm}^{2}$ laser fluence value as the best compromise between the deposition rate and the stoichiometric transfer to deposit the composite coatings for biological assays.

The thin coatings deposited at the $400 \mathrm{~mJ} / \mathrm{cm}^{2}$ laser fluence were analyzed by SEM (Figure 8). It can be seen that the thin coatings contain higher numbers of aggregates on the top of their surfaces, with diameters between 20 and $50 \mathrm{~nm}$. The surface is completely covered. Several artificial cracks were induced before SEM analysis in order to highlight this. Cross-section analysis highlights a thickness of 100-120 nm.

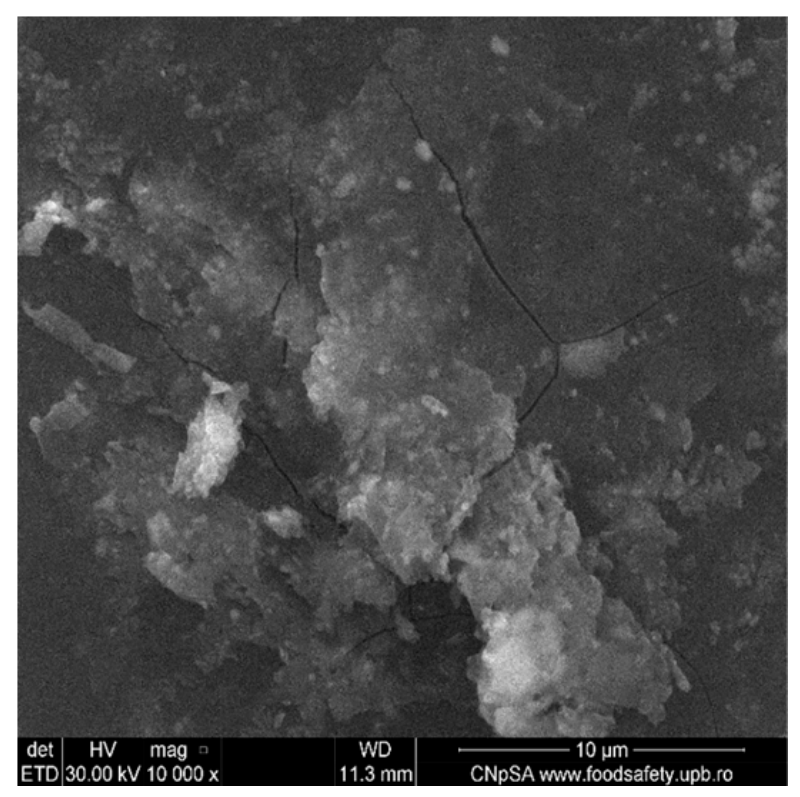

(a)

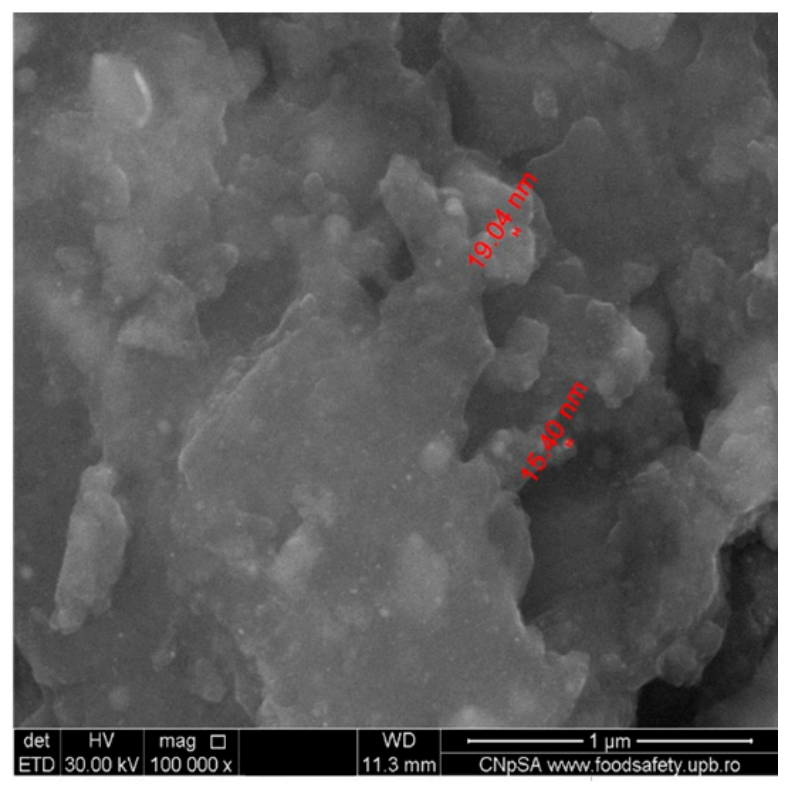

(b)

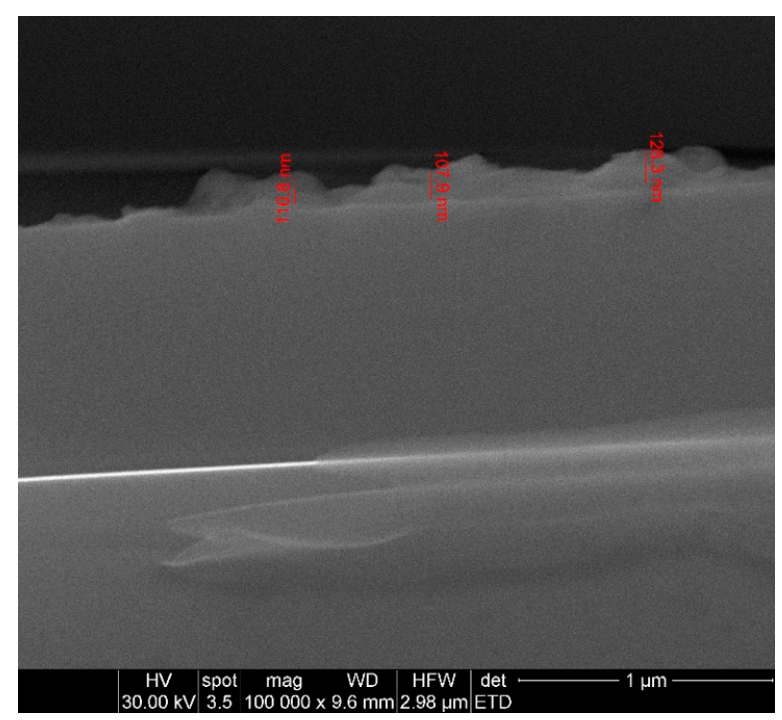

(c)

Figure 8. SEM micrographs of $\mathrm{Fe}_{3} \mathrm{O}_{4} @ \mathrm{CS} / \mathrm{LyZ}$ coating: (a,b) surface; (c) cross-section.

\subsection{Biological Evaluation of the Coatings}

\subsubsection{Cell Viability}

For the biological characterization of the obtained coatings, the percentage of metabolically active cells was evaluated through an MTT (3-(4,5-dimethylthiazol-2-yl)-2,5-dipheny- 
ltetrazolium bromide) assay on murine osteoblasts (Figure 9). It can be noted that neither $\mathrm{Fe}_{3} \mathrm{O}_{4} @ \mathrm{CS}$ nor $\mathrm{Fe}_{3} \mathrm{O}_{4} @ \mathrm{CS} / \mathrm{LyZ}$ showed cellular toxicity, as their cell viability percentages were $\sim 95 \%$ and $\sim 98 \%$ of the uncoated control, respectively. The Griess test performed to measure the nitric oxide (NO) level also led to favorable results. As it can be seen in Figure 10, the amount of NO released into the culture media was around $\sim 107 \%$ of control for both types of coatings.

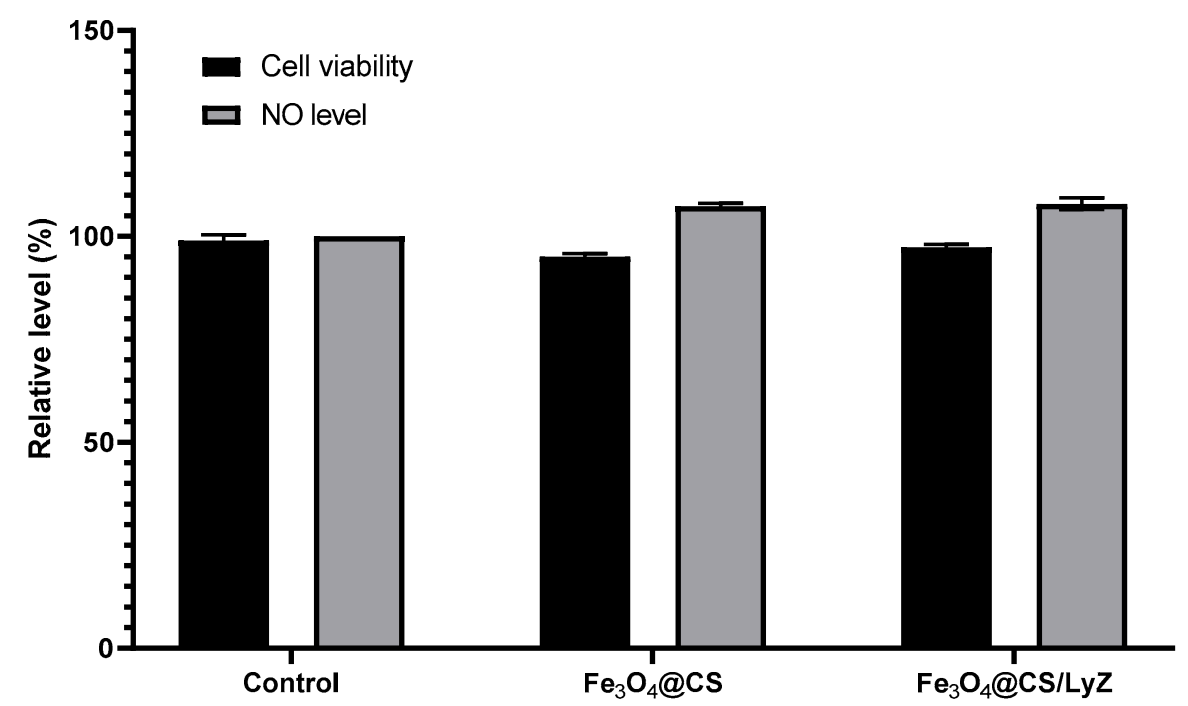

Figure 9. Cell viability and NO level after 24 h-incubation of MC3T3-E1 osteoblasts with $\mathrm{Fe}_{3} \mathrm{O}_{4} @ \mathrm{CS}$ and $\mathrm{Fe}_{3} \mathrm{O}_{4} @ \mathrm{CS} /$ LyZ samples. The results were calculated as mean values $(n=3)$ and expressed relative to control samples (uncoated substrate).
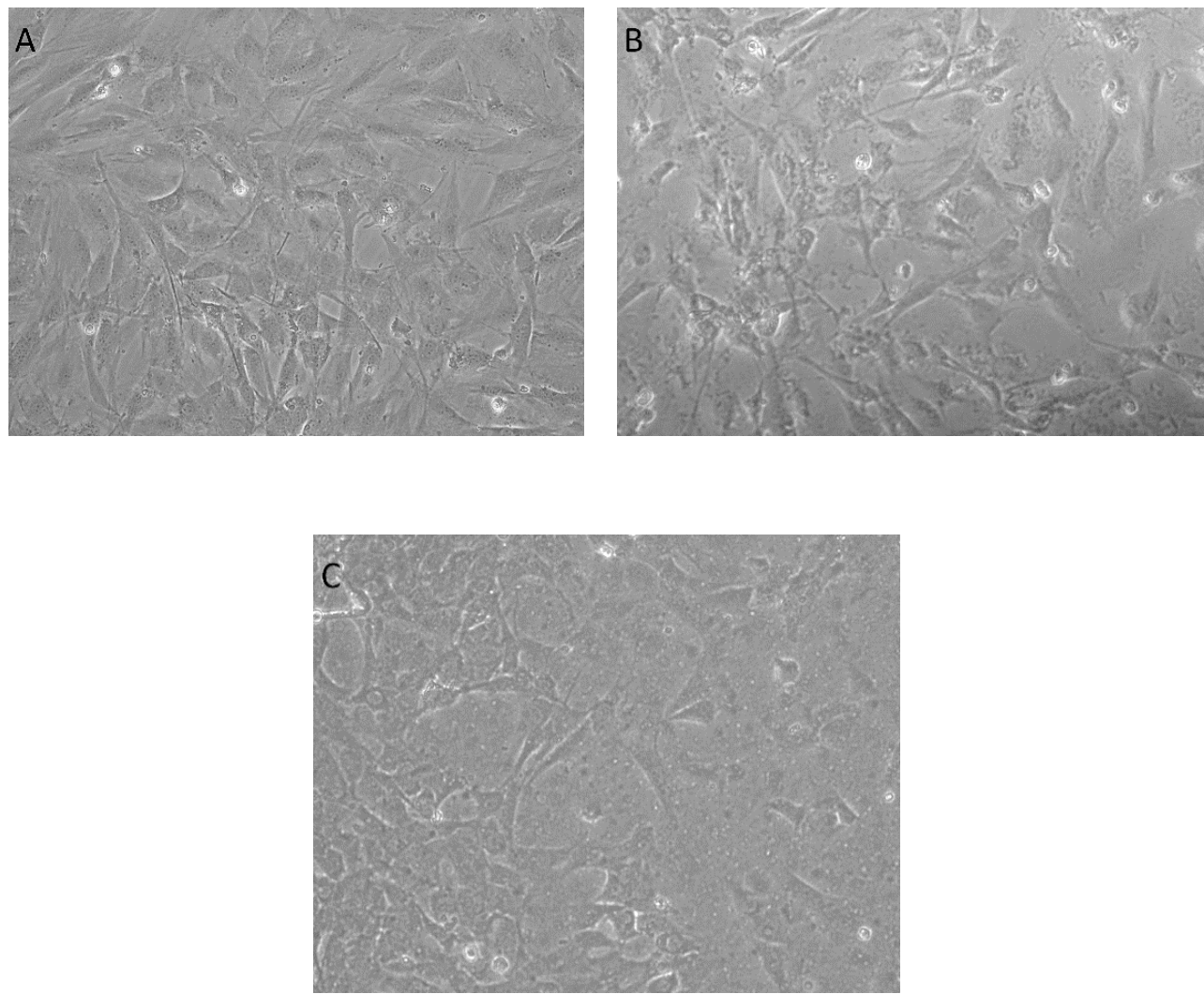

Figure 10. Phase-contrast microscopy images of osteoblasts grown for $24 \mathrm{~h}$ on (A) control, (B) $\mathrm{Fe}_{3} \mathrm{O}_{4} @ \mathrm{CS}$ coatings, and (C) $\mathrm{Fe}_{3} \mathrm{O}_{4} @ \mathrm{CS} /$ LyZ coatings (objective $10 \times$ ). 
The cell viability was also confirmed by optical microscopy images (Figure 10), as the number of healthy cells in the presence of the coatings was comparable to the number of cells grown on the control sample.

\subsubsection{Antimicrobial Tests}

Staphylococcus aureus (Gram-positive bacteria model) and Pseudomonas aeruginosa (Gram-negative bacteria model) bacteria represent two of the most infectious threats in the hospital environment because of their wide distribution, opportunistic behavior, and increasing antibiotic resistance. In this respect, the in vitro evaluation of bacterial biofilm anti-adherent properties of the prepared nanostructured coatings was assessed against both of these pathogens.

Figure 11 shows the antibiofilm results obtained for S. aureus at 24 and $48 \mathrm{~h}$ of incubation in the presence of the bioactive coatings. For this Gram-positive microorganism, a high CFU (colony forming units) $/ \mathrm{mL}$ value was registered for the control sample (magnitude order of $1.0 \times 10^{9}$ at $24 \mathrm{~h}$ and $1.0 \times 10^{11}$ at $48 \mathrm{~h}$ ). Compared to these values, the $\mathrm{Fe}_{3} \mathrm{O}_{4} @ \mathrm{CS}$ and $\mathrm{Fe}_{3} \mathrm{O}_{4} @ \mathrm{CS} /$ LyZ coatings showed much lower CFU / mL values $\left(10^{5}-10^{7}\right)$, suggesting a low ability to develop biofilms on the analyzed coatings. The biofilm inhibition ranged from 1.5 up to 4 logs, depending on the analyzed sample. Specifically, the chitosan-modified magnetite obtained values to the order $1.0 \times 10^{7}$ and $1.0 \times 10^{8} \mathrm{CFU} / \mathrm{mL}$ after 24 and $48 \mathrm{~h}$, respectively. For the $\mathrm{Fe}_{3} \mathrm{O}_{4} @ \mathrm{CS} / \mathrm{LyZ}$ sample, there were recorded values to the order of $1.0 \times 10^{5}$ at $24 \mathrm{~h}$ and $1.0 \times 10^{6}$ at $48 \mathrm{~h}$, which are much better than both the control $\mathrm{Fe}_{3} \mathrm{O}_{4} @ \mathrm{CS}$ samples. These results demonstrate the anti-adherent and antibiofilm character of both of the tested magnetite-based nanocomposites. However, the highest biofilm inhibition potential was observed for CS/LyZ containing the magnetite NP sample, suggesting a synergic antibacterial effect of Cs and LyZ (Figure 11).

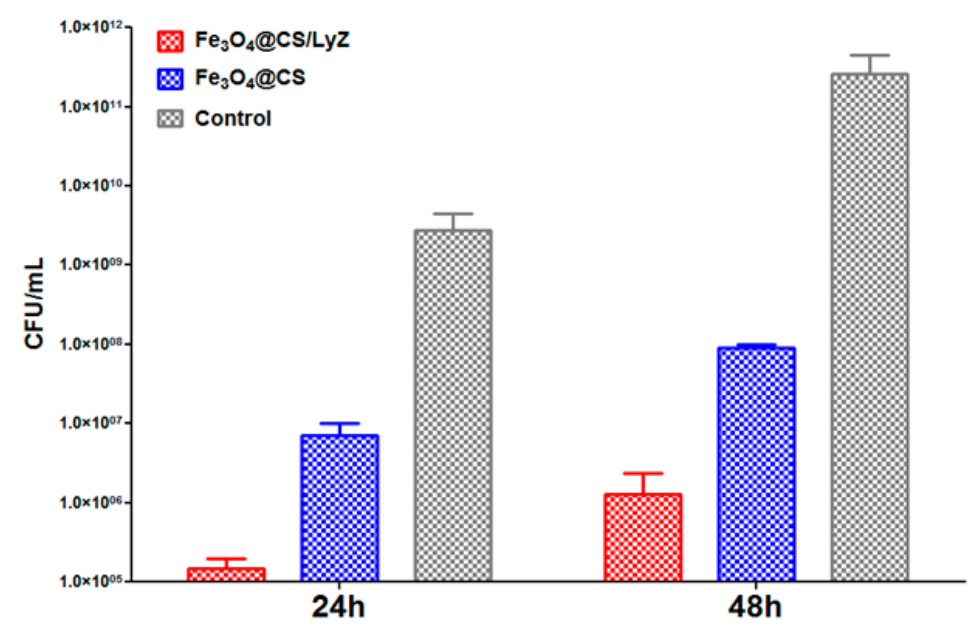

Figure 11. Evaluation of S. aureus microbial biofilm development after 24 and $48 \mathrm{~h}$ in the presence of the bioactive nanomodified coatings.

In the case of P. aeruginosa strains (Figure 12), the control CFU/mL values are to the order of $1.0 \times 10^{11}$ for both incubation periods. Compared to the control samples, the $\mathrm{CFU} / \mathrm{mL}$ values for the chitosan-modified magnetite nanocomposite are significantly lower (2-4 logs), reaching values to the order of $1.0 \times 10^{9}$ both at 24 and $48 \mathrm{~h}$ intervals. A considerable enhancement in the inhibitory character can be noted for the lysozymecontaining coating, sowing $\mathrm{CFU} / \mathrm{mL}$ values of the $1.0 \times 10^{7}$ order of magnitude after $24 \mathrm{~h}$ of incubation. However, at $48 \mathrm{~h}$, the difference between $\mathrm{Fe}_{3} \mathrm{O}_{4} @ \mathrm{CS}$ and $\mathrm{Fe}_{3} \mathrm{O}_{4} @ \mathrm{CS} / \mathrm{LyZ}$ slightly diminishes.

The obtained antimicrobial results suggest that the obtained coatings show biofilm inhibition potential for at least two days, which is very important for subsequent potential biomedical applications, such as medical implants and bioactive dressings. 


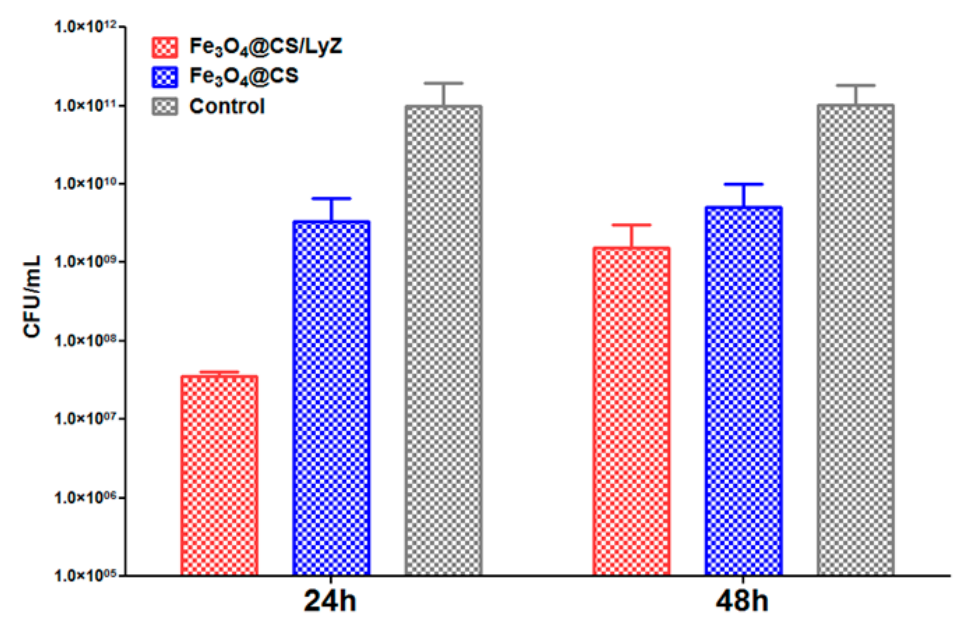

Figure 12. Evaluation of P. aeruginosa microbial biofilm development after 24 and $48 \mathrm{~h}$ in the presence of the bioactive nanomodified coatings.

\section{Materials and Methods}

\subsection{Materials}

The chemical substances required to synthesize the nanostructured materials, i.e., ferrous sulfate $\left(\mathrm{FeSO}_{4}\right)$, ferric chloride $\left(\mathrm{FeCl}_{3}\right)$, chitosan, lysozyme, acetic acid, ammonium hydroxide $\left(\mathrm{NH}_{4} \mathrm{OH}\right)$, dimethyl sulfoxide (DMSO), were purchased from Sigma Aldrich (Merck Group, Darmstadt, Germany). All chemicals were used without any further purification, and all solutions were prepared using ultrapure water (MiliQ ${ }^{\circledR}$, Merck Millipore, Burlington, MA, USA).

\subsection{Methods}

\subsubsection{Synthesis of $\mathrm{Fe}_{3} \mathrm{O}_{4} @ \mathrm{CS}$}

The $\mathrm{Fe}_{3} \mathrm{O}_{4}$ nanoparticles functionalized with $\mathrm{CS}$ were synthesized by the co-precipitation method, which involved the prior preparation of two solutions. The first solution contained the Fe precursors and was prepared by adding $1.6 \mathrm{~g}$ of $\mathrm{FeSO}_{4}$ and $1 \mathrm{~g}$ of $\mathrm{FeCl}_{3}$ into $300 \mathrm{~mL}$ of demineralized water. To this mixture, $100 \mathrm{~mL}$ of CS $1 \%$ was added. The second solution contained $9 \mathrm{~mL}$ of $\mathrm{NH}_{4} \mathrm{OH}$ and $300 \mathrm{~mL}$ of deionized water mixed under magnetic stirring. The precursor solution was added dropwise to the alkaline solution under continuous stirring. After decanting, the aqueous solution containing the reaction by-products was removed, and the powder was washed three times with deionized water. The final product was left to dry at room temperature.

\subsubsection{MAPLE Target Preparation and Deposition of Composite Coatings}

DMSO solutions of $1.5 \% \mathrm{Fe}_{3} \mathrm{O}_{4} @ \mathrm{CS}$ and $\mathrm{Fe}_{3} \mathrm{O}_{4} @ \mathrm{CS}$ blended with LyZ (2:1 wt\%) $\left(\mathrm{Fe}_{3} \mathrm{O}_{4} @ \mathrm{CS} / \mathrm{LyZ}\right)$ were prepared. All MAPLE targets were obtained by freezing the solutions poured into a pre-cooled holder at $173 \mathrm{~K}$ and were subsequently immersed in liquid nitrogen for $30 \mathrm{~min}$. The substrates were successively cleaned into an ultrasonic bath with acetone, ethanol, and deionized water, and they were then plasma-cleaned into an oxygen atmosphere for $15 \mathrm{~min}$ with a plasma system (Diener electronic, $\mathrm{GmbH}$ ). For comparison data, a control set of coatings was prepared by drop-cast on $\left(\begin{array}{lll}1 & 0 & 0\end{array}\right)$ silicon. MAPLE depositions were performed using a $\operatorname{KrF}^{*}\left(\lambda=248 \mathrm{~nm}\right.$ and $\left.\tau_{\mathrm{FWHM}}=25 \mathrm{~ns}\right)$ laser source COMPexPro 205 model (Lambda Physics-Coherent) operating at the repetition rate of $15 \mathrm{~Hz}$. The laser fluence was set in the $300-500 \mathrm{~mJ} / \mathrm{cm}^{2}$ range. All coatings were grown at a $4 \mathrm{~cm}$ target-substrate separation distance by applying $(42,000-110,000)$ subsequent laser pulses. Thin coatings were deposited onto both sides of the polished $\left(\begin{array}{lll}1 & 0 & 0\end{array}\right)$ silicon and glass substrates for IRM, SEM, and biological assays. After physico-chemical analysis we selected the $400 \mathrm{~mJ} / \mathrm{cm}^{2}$ fluence of the laser to be utilized in all of the subsequent biological tests. 


\subsubsection{Physicochemical Characterization}

XRD

The crystallinity of the obtained nanopowder was investigated by XRD using a Shimadzu XRD 6000 diffractometer. The XRD analysis was accomplished at room temperature at the Bragg diffraction angle range between 10 and $80^{\circ}$ using $\mathrm{CuK} \alpha$ radiation with $\lambda=1.056 \AA(15 \mathrm{~mA}$ and $30 \mathrm{kV})$.

\section{SEM}

To investigate the morphology and dimensions of the nanostructured thin layers, the samples were sectioned using a diamond disc placed on a support and were introduced into an FEI (Hillsboro, OR, USA) electron microscope. The obtained images were recorded using secondary electron beams at an energy of $30 \mathrm{keV}$.

\section{TEM}

For TEM investigations, a small quantity of the sample powder was dispersed in pure ethanol and was subjected to an ultrasonic treatment for $15 \mathrm{~min}$. The sample was placed on a carbon-copper grid and was left to dry at room temperature. The record the TEM micrographs, a Tecnai ${ }^{\mathrm{TM}}$ G2 F30 S-TWIN high-resolution transmission electron microscope from FEI Company (Hillsboro, OR, USA) was used in the transmission mode at a $300 \mathrm{kV}$ voltage with point and line resolutions of $2 \AA$ and $1 \AA$, respectively. The apparatus' selected area electron diffraction (SAED) accessory allowed the acquisition of additional crystallographic data.

\section{FT-IR}

To investigate the integrity of functional groups characteristic to synthesized particles, a reduced quantity of particle suspension was analyzed using a Nicolet 6700 FT-IR spectrometer from Thermo Fischer Scientific. The measurements were performed at room temperature, with 32 scans being collected at the 4000 and $1000 \mathrm{~cm}^{-1}$ range with a $4 \mathrm{~cm}^{-1}$ resolution. Recording the as-acquired information was possible by connecting the apparatus to a unity of data processing using Omnic Picta 8.2 software (Thermo Fischer Scientific). Thus, the collected spectra were overlapped, and the absorbance maps were created based on the second derivative of the spectral data.

\section{TGA-DSC}

The thermal analysis TGA-DSC for the precursors was performed with a Netzsch STA 449C Jupiter apparatus. The samples were placed in an open crucible made of alumina and were heated at $10 \mathrm{~K} \cdot \mathrm{min}^{-1}$ from room temperature up to $900{ }^{\circ} \mathrm{C}$ under the flow of $50 \mathrm{~mL}$ $\min ^{-1}$ dried air. An empty alumina crucible was used as a reference.

\subsubsection{Biological Characterization \\ Cell Viability}

To determine the cell viability of the nanocomposite films, an MTT viability assay was conducted on mouse osteoblasts MC3T3-E1 grown for $24 \mathrm{~h}$ in Minimum Essential Medium containing 10\% fetal bovine serum. The investigated thin films deposited on $\mathrm{Si}$ substrates were previously UV sterilized by exposure for $20 \mathrm{~min}$ on each side). Cells were seeded on top of uncoated and coated substrates at a cellular density of $4 \times 10^{4}$ cells $/ \mathrm{cm}^{2}$. After removing the culture medium, the cells were washed with phosphate-buffered saline (PBS). The MTT solution was added, and the cells were further incubated at $37^{\circ} \mathrm{C}$ for two hours in the dark. The MTT solution was removed and replaced with an equal volume of isopropanol to solubilize the formazan crystals thorough pipetting. The spectrophotometric absorbance measurements were performed at a $595 \mathrm{~nm}$ wavelength with the aid of a GENios TECAN microplate reader (TECAN, Männedorf, Switzerland). The cell morphology was visualized using an Olympus IX71 microscope (Olympus, Tokyo, Japan). Uncoated substrates were considered the control for the biological tests. 
The amount of NO in the collected culture medium after the osteoblasts had been incubated with the test samples for $24 \mathrm{~h}$ was measured with Griess reagent (a stoichiometric solution of $0.1 \%$ naphthylethylenediamine dihydrochloride and $1 \%$ sulphanilamide in $5 \% \mathrm{H}_{3} \mathrm{PO}_{4}$ ). Increased $\mathrm{NO}$ levels were significant for cytotoxic effects related to inflammation and apoptosis processes. The absorbance of the mix formed from culture supernatants and Griess reagent was measured at $550 \mathrm{~nm}$ using the GENios TECAN reader, and the NO concentration was calculated from the standard $\mathrm{NaNO}_{2}$ curve.

\section{Antimicrobial Effect}

To test the effect of the prepared surfaces on biofilm formation, the obtained materials were cut into $1 \mathrm{~cm} \times 1 \mathrm{~cm}$ samples and were sterilized by UV exposure for $20 \mathrm{~min}$ on each side. Each sterile fragment was individually placed in wells of a 6-well plate. An amount of $2 \mathrm{~mL}$ of nutritive broth were added to each well followed by $50 \mu \mathrm{L}$ of bacterial suspensions of $0.5 \mathrm{McF}$ arland standard densities $\left(1.5 \times 10^{8} \mathrm{CFU}\right.$ (colony forming units) $/ \mathrm{mL}$ ). The asprepared 6-well plates were incubated at $37^{\circ} \mathrm{C}$ for $24 \mathrm{~h}$. After incubation, the samples were washed with PBS, and the culture medium was changed to ensure microbial biofilm development. The plates were further incubated for $24 \mathrm{~h}$; afterward, the specimen on which biofilm was formed was washed with PBS and was placed in an Eppendorf tube containing $1 \mathrm{~mL}$ PBS. The tube was vigorously vortexed for $30 \mathrm{~s}$ to detach the biofilm cells. The obtained cell suspension was serially diluted, and different dilutions were seeded on nutritive agar in triplicate to perform viable counts and to quantify the number of colony-forming units (CFU/mL).

Biological test results were analyzed using Student's $t$-test on Excel (Microsoft Office 2018). Statistically significant data were considered as having a $p$-value of less than 0.05 .

\section{Conclusions}

This study presented the successful preparation of a nanomaterial based on chitosan and lysozyme functionalized magnetite, which is intended for future study and application in the biomedical domain. The initial nanopowders were deposited as thin coatings using the MAPLE technique and were further investigated from physicochemical and biological points of view. The developed nanostructured coating proved to have good biocompatibility and biofilm inhibitory activity against relevant opportunistic bacteria known for their biofilm infections. It was concluded that $\mathrm{Fe}_{3} \mathrm{O}_{4} @ \mathrm{CS}$ and $\mathrm{Fe}_{3} \mathrm{O}_{4} @ \mathrm{CS} / \mathrm{LyZ}$ prepared coatings have a strong antimicrobial effect while maintaining high cell viability. The higher antibiofilm effect of the $\mathrm{Fe}_{3} \mathrm{O}_{4} @ \mathrm{CS} / \mathrm{LyZ}$ coating could be explained by the synergic effects of CS and LyZ, which are both known antimicrobial agents. These results are promising for the use of the prepared materials as bioactive nanostructured coatings for medical implants, which can aid in the prevention and treatment of persistent infections caused by microbial biofilms.

Author Contributions: Conceptualization, V.A.S., V.G., A.M.G. and E.A.; methodology, G.D., V.G., A.M.H., A.M.G. and E.A.; validation, A.C.B., G.D., V.G., A.M.H., B.S.V., A.M.G., M.S.S. and E.A.; formal analysis, V.A.S., A.-G.N., S.S., A.C.B., G.D., O.-C.O., B.Ș.V., I.C.N. and M.S.S.; investigation, V.A.S., S.S., A.C.B., G.D., V.G., A.M.H., O.-C.O., B.S.V., I.C.N. and M.S.S.; resources, V.G., A.M.H., A.M.G. and E.A.; data curation, A.M.H., O.-C.O. and M.S.S.; writing-original draft preparation, V.A.S., A.-G.N., S.S., V.G., A.M.H., O.-C.O. and A.M.G.; writing-review and editing, A.-G.N., V.G., A.M.H., A.M.G. and E.A.; supervision, A.M.G. and E.A.; All authors have read and agreed to the published version of the manuscript.

Funding: This research received no external funding.

Institutional Review Board Statement: Not applicable.

Informed Consent Statement: Not applicable.

Data Availability Statement: Not applicable.

Conflicts of Interest: The authors declare no conflict of interest. 


\section{References}

1. Jamal, M.; Ahmad, W.; Andleeb, S.; Jalil, F.; Imran, M.; Nawaz, M.A.; Hussain, T.; Ali, M.M.; Rafiq, M.; Kamil, M.A. Bacterial biofilm and associated infections. J. Chin. Med. Assoc. 2018, 81, 7-11. [CrossRef] [PubMed]

2. Petrachi, T.; Resca, E.; Piccinno, M.S.; Biagi, F.; Strusi, V.; Dominici, M.; Veronesi, E. An Alternative Approach to Investigate Biofilm in Medical Devices: A Feasibility Study. Int. J. Environ. Res. Public Health 2017, 14, 1587. [CrossRef] [PubMed]

3. Kazemzadeh-Narbat, M.; Cheng, H.; Chabok, R.; Alvarez, M.M.; De La Fuente-Nunez, C.; Phillips, K.S.; Khademhosseini, A. Strategies for antimicrobial peptide coatings on medical devices: A review and regulatory science perspective. Crit. Rev. Biotechnol. 2021, 41, 94-120. [CrossRef] [PubMed]

4. Wu, K.; Yang, Y.; Zhang, Y.; Deng, J.; Lin, C. Antimicrobial activity and cytocompatibility of silver nanoparticles coated catheters via a biomimetic surface functionalization strategy. Int. J. Nanomed. 2015, 10, 7241-7252. [CrossRef]

5. Koley, S.; Mukherjee, M. Genetic Basis of Biofilm Formation and Spread of Nosocomial Infections. In Analytical Methodologies for Biofilm Research; Springer: Berlin/Heidelberg, Germany, 2021; pp. 269-298.

6. Hooshdar, P.; Kermanshahi, R.K.; Ghadam, P.; Khosravi-Darani, K. A Review on Production of Exopolysaccharide and Biofilm in Probiotics Like Lactobacilli and Methods of Analysis. Biointerface Res. Appl. Chem. 2020, 10, 6058-6075. [CrossRef]

7. Ahmadabadi, H.Y.; Yu, K.; Kizhakkedathu, J.N. Surface modification approaches for prevention of implant associated infections. Colloids Surf. B Biointerfaces 2020, 193, 111116. [CrossRef]

8. Gheorghe, D.C.; Ilie, A.; Niculescu, A.-G.; Grumezescu, A.M. Preventing Biofilm Formation and Development on Ear, Nose and Throat Medical Devices. Biomedicines 2021, 9, 1025. [CrossRef]

9. Prodana, M.; Stoian, A.B.; Burnei, C.; Ionita, D. Innovative Coatings of Metallic Alloys Used as Bioactive Surfaces in Implantology: A Review. Coatings 2021, 11, 649. [CrossRef]

10. Mihai, A.D.; Chircov, C.; Grumezescu, A.M.; Holban, A.M. Magnetite Nanoparticles and Essential Oils Systems for Advanced Antibacterial Therapies. Int. J. Mol. Sci. 2020, 21, 7355. [CrossRef]

11. Anghel, A.G.; Grumezescu, A.M.; Chirea, M.; Grumezescu, V.; Socol, G.; Iordache, F.; Oprea, A.E.; Anghel, I.; Holban, A.M. MAPLE Fabricated Fe3O4@Cinnamomum verum Antimicrobial Surfaces for Improved Gastrostomy Tubes. Molecules 2014, 19, 8981-8994. [CrossRef]

12. Polívková, M.; Hubáček, T.; Staszek, M.; Švorčík, V.; Siegel, J. Antimicrobial Treatment of Polymeric Medical Devices by Silver Nanomaterials and Related Technology. Int. J. Mol. Sci. 2017, 18, 419. [CrossRef]

13. Gherasim, O.; Grumezescu, A.M.; Grumezescu, V.; Iordache, F.; Vasile, B.S.; Holban, A.M. Bioactive Surfaces of Polylactide and Silver Nanoparticles for the Prevention of Microbial Contamination. Materials 2020, 13, 768. [CrossRef]

14. Gherasim, O.; Popescu, R.C.; Grumezescu, V.; Mogoșanu, G.D.; Mogoantă, L.; Iordache, F.; Holban, A.M.; Vasile, B.Ș.; Bîrcă, A.C.; Oprea, O.-C.; et al. MAPLE Coatings Embedded with Essential Oil-Conjugated Magnetite for Anti-Biofilm Applications. Materials 2021, 14, 1612. [CrossRef]

15. Wang, Y.; Yang, Y.; Shi, Y.; Song, H.; Yu, C. Antibiotic-Free Antibacterial Strategies Enabled by Nanomaterials: Progress and Perspectives. Adv. Mater. 2020, 32, e1904106. [CrossRef]

16. Nowak, M.; Barańska-Rybak, W. Nanomaterials as a Successor ofAntibiotics in Antibiotic-Resistant, Biofilm Infected Wounds? Antibiotics 2021, 10, 941. [CrossRef]

17. Saeed, A.; Bosch, A.; Bettiol, M.; Nossa González, D.L.; Erben, M.F.; Lamberti, Y. Novel Guanidine Compound against MultidrugResistant Cystic Fibrosis-Associated Bacterial Species. Molecules 2018, 23, 1158. [CrossRef]

18. Peng, Y.; Liu, Y.; Lu, X.; Wang, S.; Chen, M.; Huang, W.; Wu, Z.; Lu, G.; Nie, L. Ag-Hybridized plasmonic Au-triangular nanoplates: Highly sensitive photoacoustic/Raman evaluation and improved antibacterial/photothermal combination therapy. $J$. Mater. Chem. B 2018, 6, 2813-2820. [CrossRef]

19. Besinis, A.; Hadi, S.D.; Le, H.R.; Tredwin, C.; Handy, R.D. Antibacterial activity and biofilm inhibition by surface modified titanium alloy medical implants following application of silver, titanium dioxide and hydroxyapatite nanocoatings. Nanotoxicology 2017, 11, 327-338. [CrossRef]

20. Makvandi, P.; Wang, C.-Y.; Zare, E.N.; Borzacchiello, A.; Niu, L.-N.; Tay, F.R. Metal-Based Nanomaterials in Biomedical Applications: Antimicrobial Activity and Cytotoxicity Aspects. Adv. Funct. Mater. 2020, 30, 1910021. [CrossRef]

21. Chen, R.; Huang, S.; Lin, T.; Ma, H.; Shan, W.; Duan, F.; Lv, J.; Zhang, J.; Ren, L.; Nie, L. Photoacoustic molecular imaging-escorted adipose photodynamic-browning synergy for fighting obesity with virus-like complexes. Nat. Nanotechnol. 2021, 16, 455-465. [CrossRef]

22. Lv, J.; Li, S.; Zhang, J.; Duan, F.; Wu, Z.; Chen, R.; Chen, M.; Huang, S.; Ma, H.; Nie, L. In vivo photoacoustic imaging dynamically monitors the structural and functional changes of ischemic stroke at a very early stage. Theranostics 2020, 10, 816-828. [CrossRef]

23. Hu, H.; Yang, H.; Huang, P.; Cui, D.; Peng, Y.; Zhang, J.; Lu, F.; Lian, J.; Shi, D. Unique role of ionic liquid in microwave-assisted synthesis of monodisperse magnetite nanoparticles. Chem. Commun. 2010, 46, 3866-3868. [CrossRef]

24. Bezdorozhev, O.; Kolodiazhnyi, T.; Vasylkiv, O. Precipitation synthesis and magnetic properties of self-assembled magnetitechitosan nanostructures. J. Magn. Magn. Mater. 2017, 428, 406-411. [CrossRef]

25. Rajendrachari, S.; Ceylan, K.B. The activation energy and antibacterial investigation of spherical Fe3O4 nanoparticles prepared by Crocus sativus (Saffron) flowers. Biointerface Res. Appl. Chem. 2020, 10, 5951-5959. [CrossRef] 
26. Samrot, A.V.; Sahithya, C.S.; Sruthi, P.D.; Selvarani, A.J.; Raji, P.; Prakash, P.; Ponnaiah, P.; Petchi, I.; Pattammadath, S.; Purayil, S.K.; et al. Itraconazole Coated Super Paramagnetic Iron Oxide Nanoparticles for Antimicrobial Studies. Biointerface Res. Appl. Chem. 2020, 10, 6262-6269. [CrossRef]

27. Mohammadi, H.; Nekobahr, E.; Akhtari, J.; Saeedi, M.; Akbari, J.; Fathi, F. Synthesis and characterization of magnetite nanoparticles by co-precipitation method coated with biocompatible compounds and evaluation of in-vitro cytotoxicity. Toxicol. Rep. 2021, 8, 331-336. [CrossRef]

28. Niculescu, A.-G.; Chircov, C.; Grumezescu, A.M. Magnetite nanoparticles: Synthesis methods-A comparative review. Methods 2021, in press. [CrossRef]

29. Liakos, I.; Grumezescu, A.M.; Holban, A.M. Magnetite Nanostructures as Novel Strategies for Anti-Infectious Therapy. Molecules 2014, 19, 12710-12726. [CrossRef]

30. Rădulescu, M.; Andronescu, E.; Holban, A.M.; Vasile, B.S.; Iordache, F.; Mogoantă, L.; Mogoșanu, G.D.; Grumezescu, A.M.; Georgescu, M.; Chifiriuc, M.C. Antimicrobial Nanostructured Bioactive Coating Based on $\mathrm{Fe}_{3} \mathrm{O}_{4}$ and Patchouli Oil for Wound Dressing. Metals 2016, 6, 103. [CrossRef]

31. Ficai, D.; Grumezescu, V.; Fufă, O.M.; Popescu, R.C.; Holban, A.M.; Ficai, A.; Grumezescu, A.M.; Mogoanta, L.; Mogosanu, G.D.; Andronescu, E. Antibiofilm Coatings Based on PLGA and Nanostructured Cefepime-Functionalized Magnetite. Nanomaterials 2018, 8, 633. [CrossRef]

32. Habtemariam, A.B. Biosynthesis of Magnetite $\left(\mathrm{Fe}_{3} \mathrm{O}_{4}\right)$ Nanostructures using Vernonia amygdalina Leaves Extract. Lett. Appl. Nanobiosci. 2021, 10, 2777-2783.

33. de Queiroz, D.F.; de Camargo, E.R.; Martines, M.A.U. Synthesis and characterization of magnetic nanoparticles of cobalt ferrite coated with silica. Biointerface Res. Appl. Chem. 2020, 10, 4908-4913. [CrossRef]

34. Elazab, H.A.; El-Idreesy, T.T. Optimization of the catalytic performance of $\mathrm{Pd} / \mathrm{Fe} 3 \mathrm{O} 4$ nanoparticles prepared via microwaveassisted synthesis for pharmaceutical and catalysis applications. Biointerface Res. Appl. Chem. 2019, 9, 3794-3799. [CrossRef]

35. Cabrera, L.; Gutierrez, S.; Menendez, N.; Morales, M.P.; Herrasti, P. Magnetite nanoparticles: Electrochemical synthesis and characterization. Electrochim. Acta 2008, 53, 3436-3441. [CrossRef]

36. Basavegowda, N.; Baek, K.-H. Multimetallic Nanoparticles as Alternative Antimicrobial Agents: Challenges and Perspectives. Molecules 2021, 26, 912. [CrossRef]

37. Pereira, C.; Pereira, A.M.; Fernandes, C.; Rocha, M.; Mendes, R.; Fernández-García, M.P.; Guedes, A.; Tavares, P.B.; Grenèche, J.-M.; Araújo, J.P.; et al. Superparamagnetic $\mathrm{MFe}_{2} \mathrm{O}_{4}(\mathrm{M}=\mathrm{Fe}, \mathrm{Co}, \mathrm{Mn})$ Nanoparticles: Tuning the Particle Size and Magnetic Properties through a Novel One-Step Coprecipitation Route. Chem. Mater. 2012, 24, 1496-1504. [CrossRef]

38. Salvador, M.; Gutiérrez, G.; Noriega, S.; Moyano, A.; Blanco-López, M.C.; Matos, M. Microemulsion Synthesis of Superparamagnetic Nanoparticles for Bioapplications. Int. J. Mol. Sci. 2021, 22, 427. [CrossRef]

39. Sirivat, A.; Paradee, N. Facile synthesis of gelatin-coated $\mathrm{Fe}_{3} \mathrm{O}_{4}$ nanoparticle: Effect of pH in single-step co-precipitation for cancer drug loading. Mater. Des. 2019, 181, 107942. [CrossRef]

40. Shabatina, T.I.; Vernaya, O.I.; Shabatin, V.P.; Melnikov, M.Y. Magnetic Nanoparticles for Biomedical Purposes: Modern Trends and Prospects. Magnetochemistry 2020, 6, 30. [CrossRef]

41. Joseph, S.M.; Krishnamoorthy, S.; Paranthaman, R.; Moses, J.A.; Anandharamakrishnan, C. A review on source-specific chemistry, functionality, and applications of chitin and chitosan. Carbohydr. Polym. Technol. Appl. 2021, 2, 100036. [CrossRef]

42. Velgosova, O.; Mudra, E.; Vojtko, M. Preparing, Characterization and Anti-Biofilm Activity of Polymer Fibers Doped by Green Synthesized AgNPs. Polymers 2021, 13, 605. [CrossRef]

43. Fernandes, T.A.; Costa, I.F.M.; Jorge, P.; Sousa, A.C.; André, V.; Cerca, N.; Kirillov, A.M. Silver(I) Coordination Polymers Immobilized into Biopolymer Films for Antimicrobial Applications. ACS Appl. Mater. Interfaces 2021, 13, 12836-12844. [CrossRef]

44. Chang, C.-T.; Chen, Y.-T.; Hsieh, Y.-K.; Girsang, S.P.; Wang, R.S.; Chang, Y.-C.; Shen, S.-H.; Shen, C.R.; Lin, T.-P.; Wan, D.; et al. Dual-functional antibiofilm polymer composite for biodegradable medical devices. Mater. Sci. Eng. C Mater. Biol. Appl. 2021, 123, 111985. [CrossRef]

45. Tiplea, R.E.; Lemnaru, G.-M.; Trușcă, R.D.; Holban, A.; Kaya, M.G.A.; Dragu, L.D.; Ficai, D.; Ficai, A.; Bleotu, C. Antimicrobial Films based on Chitosan, Collagen, and ZnO for Skin Tissue Regeneration. Biointerface Res. Appl. Chem 2020, 11, 11985-11995.

46. Tawfik, T.M.; El-Masry, A.M.A. Preparation of Chitosan Nanoparticles and its Utilization as Novel Powerful Enhancer for Both Dyeing Properties and Antimicrobial Activity of Cotton Fabrics. Biointerface Res. Appl. Chem 2021, 11, 13652-13666.

47. Tiama, T.M.; Elhaes, H. Application of Chitosan/ $\mathrm{Fe}_{3} \mathrm{O}_{4}$ Nanocomposite as Biosensor. Lett. Appl. Nanobiosci. 2020, 10, $2438-2445$.

48. Gomes, A.C.; Mohsen, M.; Bachmann, M.F. Harnessing nanoparticles for immunomodulation and vaccines. Vaccines 2017, 5, 6. [CrossRef]

49. Kubackova, J.; Zbytovska, J.; Holas, O. Nanomaterials for direct and indirect immunomodulation: A review of applications. Eur. J. Pharm. Sci. 2019, 142, 105139. [CrossRef]

50. Ali, S.F.A.; Gad, E.S. Investigation of an adsorbent based on novel starch/chitosan nanocomposite in extraction of indigo carmine dye from aqueous solutions. Biointerface Res. Appl. Chem. 2020, 10, 5556-5563. [CrossRef]

51. Ullah, F.; Javed, F.; Zakaria, M.R.; Jamila, N.; Khattak, R.; Khan, A.N.; Akil, H.M. Determining the molecular-weight and interfacial properties of chitosan built nanohydrogel for controlled drug delivery applications. Biointerface Res. Appl. Chem. 2019, 9, 4452-4457. [CrossRef] 
52. Nehra, P.; Chauhan, R.P.; Garg, N.; Verma, K. Antibacterial and antifungal activity of chitosan coated iron oxide nanoparticles. Br. J. Biomed. Sci. 2018, 75, 13-18. [CrossRef]

53. Benbow, N.L.; Sebben, D.A.; Karpiniec, S.; Stringer, D.; Krasowska, M.; Beattie, D.A. Lysozyme uptake into pharmaceutical grade fucoidan/chitosan polyelectrolyte multilayers under physiological conditions. J. Colloid Interface Sci. 2020, 565, 555-566. [CrossRef]

54. He, L.; Cui, Y.; Zhang, C. The corrosion resistance, cytotoxicity, and antibacterial properties of lysozyme coatings on orthodontic composite arch wires. RSC Adv. 2020, 10, 18131-18137. [CrossRef]

55. Saito, H.; Sakakibara, Y.; Sakata, A.; Kurashige, R.; Murakami, D.; Kageshima, H.; Saito, A.; Miyazaki, Y. Antibacterial activity of lysozyme-chitosan oligosaccharide conjugates (LYZOX) against Pseudomonas aeruginosa, Acinetobacter baumannii and Methicillin-resistant Staphylococcus aureus. PLoS ONE 2019, 14, e0217504. [CrossRef]

56. Cerón, A.A.; Nascife, L.; Norte, S.; Costa, S.A.; Nascimento, J.H.O.D.; Morisso, F.D.P.; Baruque-Ramos, J.; Oliveira, R.C.; Costa, S.M. Synthesis of chitosan-lysozyme microspheres, physicochemical characterization, enzymatic and antimicrobial activity. Int. J. Biol. Macromol. 2021, 185, 572-581. [CrossRef]

57. Vasile, B.S.; Oprea, O.; Voicu, G.; Ficai, A.; Andronescu, E.; Teodorescu, A.; Holban, A. Synthesis and characterization of a novel controlled release zinc oxide/gentamicin-chitosan composite with potential applications in wounds care. Int. J. Pharm. 2014, 463, 161-169. [CrossRef]

58. Motelica, L.; Ficai, D.; Ficai, A.; Truşcă, R.-D.; Ilie, C.-I.; Oprea, O.-C.; Andronescu, E. Innovative Antimicrobial Chitosan/ZnO/AgNPs/Citronella Essential Oil Nanocomposite-Potential Coating for Grapes. Foods 2020, 9, 1801. [CrossRef]

59. Mohammed, H.B.; Rayyif, S.M.I.; Curutiu, C.; Birca, A.C.; Oprea, O.-C.; Grumezescu, A.M.; Ditu, L.-M.; Gheorghe, I.; Chifiriuc, M.C.; Mihaescu, G.; et al. Eugenol-Functionalized Magnetite Nanoparticles Modulate Virulence and Persistence in Pseudomonas aeruginosa Clinical Strains. Molecules 2021, 26, 2189. [CrossRef] 